\title{
XVIII. On some effects of twist on the thermo- electric qualities of iron
}

\section{K. Tsuruta}

To cite this article: K. Tsuruta (1900) XVIII. On some effects of twist on the thermoelectric qualities of iron, Philosophical Magazine Series 5, 50:303, 223-231, DOI: 10.1080/14786440009463906

To link to this article: http://dx.doi.org/10.1080/14786440009463906

册 Published online: 21 Apr 2009.

Submit your article to this journal $[\pi$

Џlll Article views: 3

Q View related articles $\square$ 
Effects of Twist on the Thermo-electric Qualities of Iron. 223

(7) Hydrogen and the cosmic pioneers then become a trap for wandering bodies that tend to be stopped and converted into dense nebulæ.

(8) These dense nebula tend to attract surrounding gas; they cool and shrink, some ultimately forming solid bodies.

(9) These bodies, by mutual attraction, give density to the new cosmic system.

(10) Such systems are of the first order.

(11) The impact of systems of the first order produces systems of the second order.

(12) Any other impacts produce systems of the third order, of which our galactic system is a type.

(13) The coalescence of two cosmic systems does not necessarily, as a final result, produce a system of a larger mass than the two original systems from which it was formed, as many agencies are tending to send matter out of the coalesced mass.

(14) It is thus seen that dissipation of energy is but a part of a complex cyclical process; and there is consequently the possibility of an immortal cosmos in which we have neither evidence of a beginning nor promise of an end, the present being but a phase of an eternal rhythm.

The accompanying diagrammatic scheme illustrates these agencies. It must be noted that bodies and systems are printed in italic capitals; and where several such are one above another it implies sequence of phenomena.

XVIII. On some Effects of Twist on the Thermo-electrie Qualities of Iron. By K. Tsuruta (Tokyo, Japan), in Gottingen".

THIS formed one of my old subjects of investigation, in 1 fact, should have formed the continuation of my papers published in the 'Journal of the College of Seience, Imperial 'University, Tokyo.' In 1892 some preliminary experiments, and in 1895 the present series of experiments, were carried ovt ; but as my methods had to be improved upon, and the results then obtained appeared likely to be correoted in seme or other points, I refrained from having them published along with the others. Up to this day, however, I have not been able, and still at present I see no prospect of being able, to exeeute my intention. On the other hand there have lately come to my knowledge some papers dealing with somewhat alliod * Communicated by the Author. 
subject-matters-for example, G. Meyer's in Wiedemann's Annalen, and G. Maclean's in the 'Proceedings of the Royal Society of London.' Having been thus reminded of my old experiments, I have been led to do my best to give now and here an account of them, inasmuch as I believe that though unfinished and incomplete, yet if communicated to fellowworkers interested in such matters, they may not be deemed utterly worthless. In undertaking this task at a date remote from the time of actual experiments I cannot feel myself sure of being free from consequences arising out of a long dismissal of the subject-matter, although my laboratory-journal, to collect my materials from, has been kept unimpaired, and the general features of my result were at that time carefully written out. The publication of this confessedly incomplete account will, I hope, call forth my colleagues' criticism and correction, affording, I doubt not, what I myself could not till now.

G. Wiedemann, in a paper on "Magnetische Untersuchnngen," after remarking that as E. Cohn has found a thermoelectric current produced in a wire, a part of which is stretched and the remainder is not, so the same might take place in regard to twisting, goes on to say that he has confirmed this by experiment, but it is not to be ascertained how he did so. At the time of my experiments I could find no paper in which the present subject is systematically treated of.

The following was one of the arrangements used in iny experiments of 1892 , and may be considered as corresponding to the well-known one of Lord Kelvin's in regard to the effect of longitudinal tension. A long piece of wire to be examined, being passed through a brass bar, was clamped to it at its middle part. One half of the wire could be twisted by means of a torsion-head at its free end, the whole being stretched by means of leaden weights applied to the other free end. A pair of small circular brass disks was fixed on the wire near its free ends and dipped into mercury pools which were connected with the electrodes of a small galvanometer. Heat was to be applied at the clamped middle of the wire. This arrangement, simple and good in principle, presented many practical difficulties, and so no quantitative observations were made.

The arrangement adopted in the year 1895 corresponds in principle to that adopted by $\mathbf{E}$. Cohn in his investigation on the thermo-electric effects of longitudinal tension. A torsionhead used was constructed in the following way:-Its outer cylindrical piece, which was to be fixed, had an inner piece (also cylindrical) fiting accurately and easy to turn. This 
inner piece had a pyramidal hollow, into which there fitted accurately a solid pyramid (of course truncated). This latter consisted of two equal wedges, which had grooves, forming together a small hole along the axis of the torsion-head, and of a calibre just sufficient to allow the end of the experimental wire to pass through. A strong screw was to be driven against the bases of the two wedges, which, on being thus pushed from behind into the pyramidal hollow, embraced the end of the wire and held it firmly in position. All was made of brass. Thus the trouble of soldering once in each experiment the end of the wire to the inner piece was obviated, but at the same time the wire was laterally and considerably compressed - a thing to be avoided as much as possible, for though the portion compressed was just next to the uncompressed, yet a difference of temperature between them (exposed and unexposed to the air as they were) might produce disturbance.

The outer piece of the torsion-head had a shallow triangular groove, cut parallel to its axis and on its outer surface. One end of the unaffected part of the experimental wire was there put in, and secured in position by a uumber of tnrns of wire.

Rigidly connected with the inner piece there was a circular disk of very hard wood provided with ten notches round its periphery. These notches served the double purpose of counting the amount of twist applied and of keeping the inner piece so turned in position by means of a side ratchet. It was this disk that was taken hold of in twisting, and thus the metallic parts were entirely free from possible disturbances due to contact with the hands.

The junction at the other free end of the part to be twisted was effected by means of another arrangement very similar to the last in construction, except that the outer and inner pieces were now made a sliding pair in order to allow for the stretching of the whole wire when loaded, and that the end of it to be joined was bere put between the two wedges side by side with an end of another part which was to be left unaffected.

The two pieces which formed the junctions were firmly mounied on a very strong block of wood at a distance of about $70 \mathrm{~cm}$. from each other, care being taken to bave them well centered in order to avoid the production of bends near the clamped ends in stretching the wire with weights. This centering and necessary adjustments were done carefully once for all, for though I had no time to demonstrate, yet it was surmised that if any bends were formed in the initial act of stretching, and were further subject to frequent 
twisting and untwisting, the effects anticipated would come out considerably complicated, though otherwise simple.

Heat was applied to the second junction by means of steam sent into a hollow vessel of brass surrounding it.

To begin with, the experimental wire was well annealed, and at the same time straightened. It was cut into three parts, each of a proper length. The ends of two of these $\rightarrow$ one the longest and to be twisted, and the other to remain unaffected-were first fixed to the second junction-piece, and put in position. Then the outer end of the part to be twisted was passed through the first junction-piece, and was firmly held there, as explained above, with the help of two small spanners, so as to avoid as much as possible any arbitrary initial twisting. One end of the remaining third part, which was to remain unaffected, was secured in position as explained above. The free ends of the two idle wires were dipped in mercury contained in two test-tubes, and surrounded with a large quantity of water, the whole being then put in a box with thick wooden walls.

The galvanometer used was of low resistance, and made highly sensitive with a controlling magnet or two. The ordinary arrangement of rocker and six mercury pools served as commutator, which it was necessary to have on account of the high sensitiveness of the galvanometer with incessant changes of zero. The commutator seems to have been a considerable source of disturbance, as different metals came here into contact ( $I$ had not at that time that form of commutator which was used in my other investigations). Absolute measurements of the current produced were, to my extreme regret, reserved to later occasions; in the curves given below the current-strength is indicated only in scale-divisions.

In my arrangement there are, it will be seen, many things which must be improved or replaced by others, some of which in fact I have put on record in my journal. All these untried things must be omitted, and of the results I obtained only the following three points seem to deserve place here.

(a) As it was thought that thermo-electric effects of twist, if any, would show themselves more conspicuously in the case of iron than with other metals, as had been the case with reference to longitudinal tension, it was soft iron that l examined first of all. The experimental wire was, to begin with, subject to the tension of some leaden weights, and then it was twisted and untwisted two or three times by way of drilling; definitive abservations were then made. The deflexion given as corresponding to a given amount of twist must be in reality the result of the superposed deflexions due to longitudinal tension and twist applied. The pure effect of twist can properly be 
gathered from obselvations with small loads; but only a fow of sueh were made-made simply for the sake of sounding, so to speak.

In fig. 1 is given a series of observations I obtained early in the course of my investigation. It seems to establish the existence of the phenomonon of thermo-electric hysteresis with respect to twist (in my own case, combined with a certain amount of longitudinal tension):

Starting from the axis of zero twist, we have an ascending trend and then a maximum point-a feature which also exists in soft iron once stretched permanently and subject to the influence of increasing longitudinal tension. This is evidently a result of the interaction between the hysteresis and the actual and immediate effect of twist. As the amount of twist is increased, the latter soon overpowers the former, causing the curve to descend. On being untwisted the wire seems to respond, yet with the hysteresis in action. The return brinch falls below the direct, continues to ascend even beyond the axis of zero twi-t, and not far from it attains again a maximum point, which is almost symmetrically situated with respect to the axis against the first maximum. Further untwisting produces the same state of things as on twisting. In short, the whole appearance of the curve is very similar to that of the well-knowis curve of magnetization and twist.

It is hardly necessary to mention after what has been siid above, that as several sources of disturbance were but imperfectly eliminated in my experiments, some curves I obtaimed were not so good as the one just cited ; for example, the maximum points were both found on the positive or both on the negative side of the axis of zero twist. It sometimes happened that one of the cycles gone through in succession was shifted relatively to the other (fig. 2). This may be partly explained by the fact of my having merely taken scale-readings.

It is ta be regretted that I did not try many samples of soft iron to see whether the hysteresis phenomenon does exist in them all. But as the

Fig. 2.

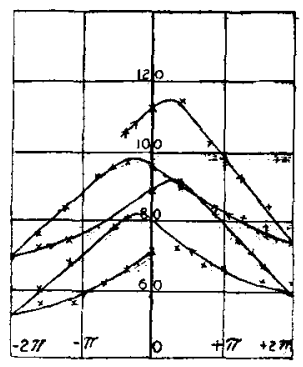
samples I tried were taken at random, it seems exceedingly imprabable that the phenomenon is confined to them alone.

(b) Such, 1 believed, might be taken as the normal type for 
soft iron when twisted and untwisted within a moderate range and, what is not to be omitted, under a moderate amount of longitudinal tension. However, $l$ then came across a curious circumstance as I went on to widen the range of twist. lmmediately after the curve of fig. $3 a$

Fig. 3.

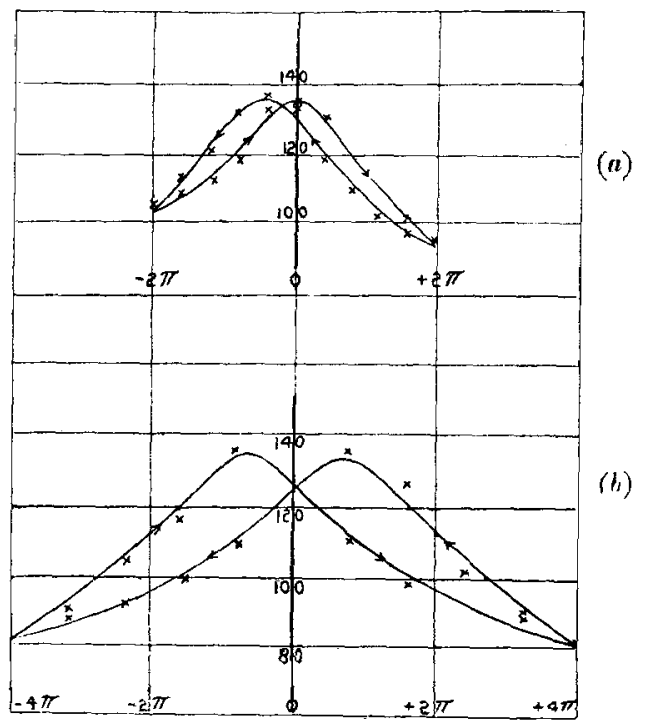

hud been obtained with the same wire and within the same range as the previous, the readings plotted in fig. $3 b$ were taken for the range of $\pm 4 \pi$, of course with the process of drilling the wire interposed. It will be observed that with all the other features the same in both cases, the direct branches in the latter are below the back branches, while in the former their relative positions are reversed.

As this was discovered in the particular piece of wire within the range of twist $\pm 2 \pi$ and $\pm 4 \pi$, it seemed to me worthy of being repeatedly examined even with that particular piece; and I made many series of observations on it. It may be cited that I tried to get a number of curves for different ranges one after another, and each preceded by the process of drilling. Thus the following four sets:(1) $\pm 10 \cdot \frac{2 \pi}{5}$, fig. $4 a ;(2) \pm 8 \cdot \frac{2 \pi}{5} ;$ fig. $4 b ;(3) \pm 6 \cdot \frac{2 \pi}{5}$ fig. $4 c ;(4) \pm 4 \cdot \frac{2 \pi}{5}$, fig. $4 d$. The general features of all the curves are similar, and the bysteresis phenomenon is 
apparent. In the first figure the direct and back branches are distinctly separated from each other, the former lying below the latter. In the second figure the distinction between

(c)

Fig. 4.

(a)

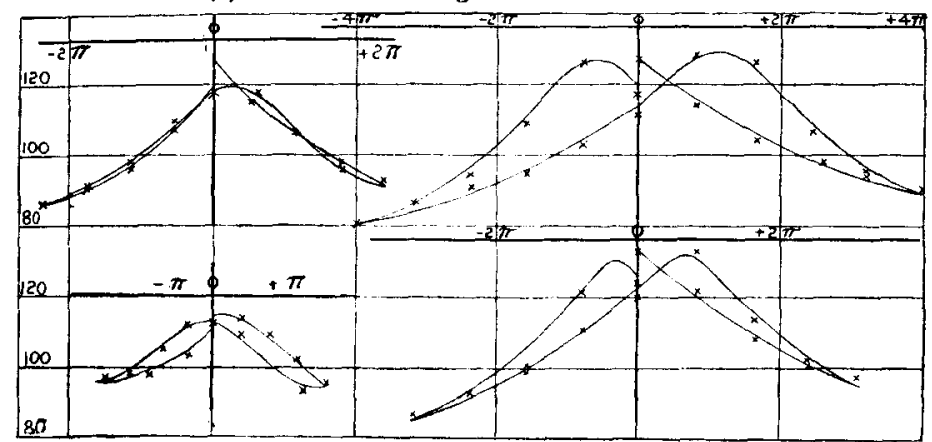

(d)

(b)

the branches becomes less, yet their relative positions are maintained. In the third figure the branches cross each other, suggesting that the metamorphosis from one type to the other is here or hereabout taking place. And in the fourth figure we have the type originally obtained, and believed to be normal.

I cannot here help referring to a very similar feature discovered in the course of Prof. Nagaoka's magnetic investigations, called by him the "reversal of hysteresis" *.

I may also cite one of my experiments made on another piece of wire cut from the same bundle as the previous, in which different ranges of twist were gone through in succession, and with all the intervening processes of drilling omitted. It was to be expected that somewhere in the chain the reversal would come into view. Suffice it to state that the experiment fully confirmed the expectation.

Experiments with still another piece, cut from the same bundle and with the range of twist widened up to $\pm 6 \pi$ and even to $\pm 8 \pi$, show that the type of the curves obtained is in all cases preserved, and that the direct and back branches become more and more distinct, with the two maximum points separating asunder the more widely the greater are the ranges of twist.

Examination of many different samples is also here wanting.

* Journ. of the Coll, of Science, Imperial University, Tokyo, vol, iii. pp. 189-207.

Phil. Mag. S. 5. Vol. 50. No. 303. Aug. $1900 . \quad$ R 
(c) The third and last result I have to communicate refers to the effect of agitation in the form of brisk tapping, which is known to be quite marked in the case of longitudinal tension. The agitation seems to be lass efiective in the present than in that case; yet is quite sensible. The two pairs of curves, figs. $5 a, 5 b$, and figs. $6 a, b b$, will give an idea of
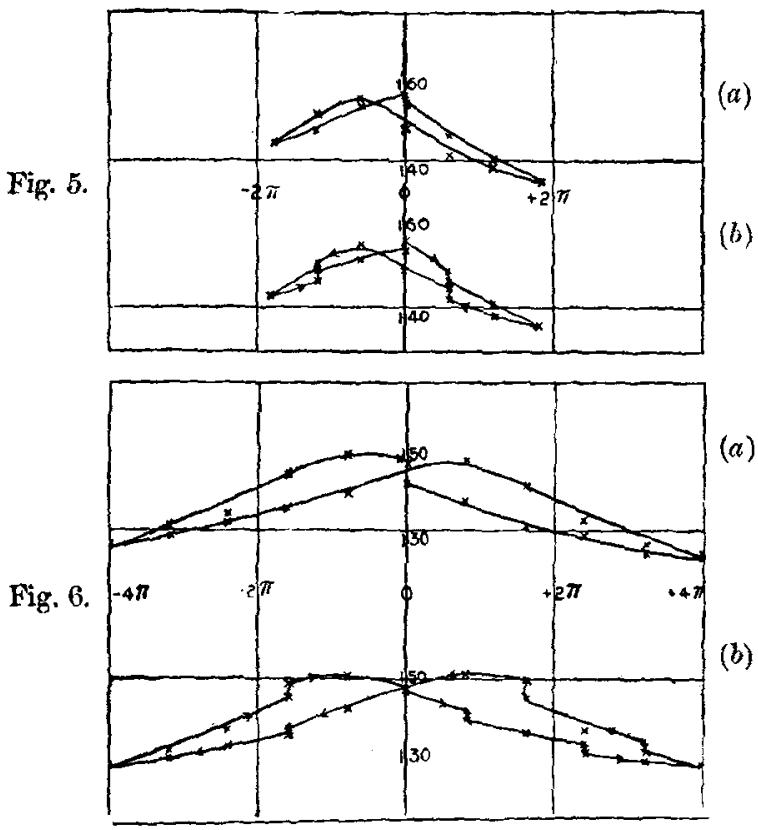

the effect. One of each yair refers to a series of observations made as usual, and the other to the immediately succeeding one in which there was interposed at some easily distinguishable point the operation of tapping (namely, with a wooden rod on the stretched rope by which the leaden weights were suspended). The former pair has the range of twist within the critical value of twist for the reversal, while in the latter it lies beyond it. The effect of agitation seems in both cases to be opposite on the direct and back branches, on one side as well as the other of the axis of zero twist; so that agitation has in figs. 5 the tendency to make the branches approach towards each other, and in figs. 6 to separate from each other. Hence it was expected that it might be possible by continual tapping to pass from the second type of the curres (i. e. after the reversal) to the first (i.e. previons to it). Thi: seems to have been but partially fulfilled in a few experiments 
On the Action of Copper-Zine Alloys on Nitric Acid.

tried; for I find that in some cases the branches only approach considerably towards each other, while in other cases they merely cross each other, but never entirely reverse their relative positions as expected.

It seems, then, that I was able to show by the above experiments, defective and incomplete as they were:-

(a) That in soft iron of certain kinds there exists the phenomenon of thermo-electric hysteresis with respect to twist (at least when combined with longitudinal tension);

(b) That, other things being equal, the hysteresis is reversed at a certain twist ;

(c) And that mechanical agitation has its own effects, which are reversed as the hysteresis is reversed.

XIX. On the Want of Uniformity in the Action of CopperZine Alloys on Nitric Acid. By Dr. J. H. GLadstone, F.R.S.*

M

$\mathrm{UCH}$ attention is being directed at the present time to methods by which it may be possible to determine the heat evolved in the formation of alloys. Among these methods is that of the dissolution of filings of the alloys of copper and zinc in nitric acid, as compared with the dissolution of mixtures of the two metals in the same proportion. This method has been objected to by more than one chemist on the ground that there is no assurance that the same substances, and in the same relative proportions, are produced in each case. As my name appears on the British Association Committee which has adopted this method, I have felt myself under an obligation to make some direct experiments on the point.

In the Report of this Committee, "On the Heat of Combination of Metals in the Formation of Alloys," read at the Dover Meeting of the British Association (Report, 1899, p. 246) a table is given containing details of a long series of observations, which show the heat developed during the action of nitric acid on copper and zine in various proportions, both when the metals are mixed together and when they are in combination as alloys. The difference of heat between the solutions compared has been regarded as a measure of the heat evolved by the combination of the metals in forming the alloy.

The alloys experimented upon by Dr. Galt are twenty-two in number. The results are set out in a table, and plotted in

* Communicated by the Physical Society : read May 11, 1900.

\section{R 2}

